\title{
Impact of IL8 and IL8-Receptor alpha polymorphisms on the genetics of bronchial asthma and severe RSV infections Beena Puthothu ${ }^{1}$, Marcus Krueger ${ }^{1}$, Jessica Heinze ${ }^{1}$, Johannes Forster ${ }^{1,2}$ and Andrea Heinzmann*1
}

\author{
Address: ${ }^{1}$ University Children's Hospital, University of Freiburg, Mathildenstrasse 1, D-79106 Freiburg, Germany and ${ }^{2}$ St. Josefhospital, Sautier \\ Str. 1, D-79104 Freiburg, Germany \\ Email: Beena Puthothu - beenamary@hotmail.com; Marcus Krueger - krueger@kikli.ukl.uni-freiburg.de; Jessica Heinze - jessica-heinze@web.de; \\ Johannes Forster - Johannes.Forster@rkk-sjk.de; Andrea Heinzmann* - heinzmann@kikli.ukl.uni-freiburg.de \\ * Corresponding author
}

Published: 17 February 2006

Clinical and Molecular Allergy 2006, 4:2 doi:10.1186/1476-7961-4-2
Received: 27 December 2005

Accepted: 17 February 2006

This article is available from: http://www.clinicalmolecularallergy.com/content/4/I/2

(c) 2006 Puthothu et al; licensee BioMed Central Ltd.

This is an Open Access article distributed under the terms of the Creative Commons Attribution License (http://creativecommons.org/licenses/by/2.0), which permits unrestricted use, distribution, and reproduction in any medium, provided the original work is properly cited.

\begin{abstract}
Background: Interleukin 8 (IL8) belongs to the family of chemokines. It mediates the activation and migration of neutrophils from peripheral blood into tissue and hereby plays a pivotal role in the initiation of inflammation. Thus it is important in inflammatory lung diseases like bronchial asthma or severe infections by Respiratory Syncytial Virus (RSV). IL8 acts through binding to the IL8-Receptor alpha (IL8RA). For both genes association with asthma has been described. In addition, IL8 has been found in association with RSV bronchiolitis. The aim of our study was to test both genes for association with asthma and severe RSV infections. In addition we were interested in whether a common genetic background of both diseases exists in regards to these genes.
\end{abstract}

Methods: We genotyped the two IL8 promotor polymorphisms $-25 \mathrm{IA} / \mathrm{T}$ and $-78 \mathrm{IC} / \mathrm{T}$ and the three amino acid variants M3IR, S276T and R335C in IL8RA on 322 children with asthma, I3I infants with severe RSV associated diseases and 270 controls. Statistical analyses made use of the Armitage's trend test for single polymorphisms and FAMHAP for calculations of haplotypes.

Results: We found association of the IL8 polymorphism $-78 \mathrm{IC} / \mathrm{T}$ as well as IL8 haplotypes with asthma $(p=0.01 \mathrm{I}$ and $p=0.036$, respectively). In addition, direct comparison of the asthmatic population with the RSV population revealed significant differences, both for $-78 \mathrm{IC} / \mathrm{T}$ alone $(\mathrm{p}=$ $0.034)$ and IL8 haplotypes $(p=0.005)$. The amino acid variants in IL8RA were evenly distributed in between all three populations.

Conclusion: We conclude from our data that IL8 might play a role in the genetic predisposition to asthma and that these effects are different or even opposite to the effects on severe RSV diseases. Furthermore, IL8RA is unlikely to play a major role in the genetics of either disease.

\section{Background}

Interleukin 8 (IL8) is a member of the chemokine family and is produced by a wide range of cell types like monocytes, macrophages, fibroblasts and ceratinocytes. It pri- marily mediates the activation and migration of neutrophils from peripheral blood into tissue and is involved in the initiation and amplification of inflammatory processes, which occur in the human immune system 
in response to a wide variety of pathogens [1]. Thus IL8 play an important role in inflammatory lung diseases like bronchial asthma or severe infections caused by respiratory syncytial virus (RSV).

RSV, a single-stranded RNA virus, is involved in at least $70 \%$ of cases of infectious infantile bronchiolitis and has been repetitively linked to asthma. It has been hypothesized that severe RSV infection in infancy might lead to the development of recurrent wheezing and/or bronchial asthma [2,3], and consequently a common genetic background of both diseases has been discussed [4]. According to the current evidence, genetic and environmental factors determine the type of immune response to RSV infection. Furthermore, this response may affect the development of control mechanisms in the regulation of airway diseases, mainly bronchial asthma.

Increased concentrations of IL8 have been described in the bronchoalveolar fluid and sputum of asthmatic patients [5]. In addition, repeated administration of IL8 into the airways induces bronchial hyperreactivity in guinea pigs [6,7]. Genetic association of IL8 has been described with asthma [8] and RSV bronchiolitis $[9,10]$.

IL8 binds with high affinity to two different receptors: IL8 receptor alpha (IL8RA, CXCR1) and beta (IL8RB, CXCR2). These closely related proteins are members of the superfamily of receptors, which couple to guanine nucleotide binding proteins. IL8RA is localized on chromosome 2q35 [11], where linkage to total serum IgE levels in asthmatics has been described [12]. In addition, association of IL8RA polymorphisms has recently been described with asthma and chronic obstructive pulmonary disease [13].

We were interested in the relationship between severe RSV infection and/or bronchial asthma and IL8 and IL8RA polymorphisms in the German population. We chose to study two IL8 promoter polymorphisms (-251A/T and $781 \mathrm{C} / \mathrm{T}$ ) and three amino acid variants in IL8RA (M31R, S276T and R335C), which are located in the N-terminus of the protein, in the third extracellular loop and in the Cterminus of the protein respectively. The selection of the IL8 polymorphisms was based on previous studies in our asthmatic and control populations, in which these polymorphisms were shown to be most informative [8].

\section{Materials and methods \\ Subjects}

Asthmatic population

322 children with bronchial asthma (aged 5 to 18 years) were recruited from the South-Western part of Germany between July 2000 and January 2005. All probands were characterized at the University Children's Hospital, Freiburg, Germany using a standardized clinical protocol. An extended medical history was recorded including the occurrence and duration of wheezing symptoms; previous and acute medications; severity of previous asthma attacks; previous allergic rhinitis or conjunctivitis; atopic dermatitis and any family history of allergic diseases.

The diagnosis was based on a clear-cut history of asthmatic symptoms; the use of anti-asthmatic medication and the presence of bronchial hyper-reactivity. The antiasthmatic drugs included typical betamimetics like salbutamol and standard corticosteroids used in asthma treatment like budesonide. Bronchial hyper-reactivity was defined as a fall in forced respiratory volume in one second (FEV1) by at least 15\% in histamine testing or exercise provocation, using standard protocols [14]. The exact recruitment procedure has been described in detail previously [15].

\section{Population of children with severe RSV infection}

This population was recruited at the University Children's Hospital, Freiburg, Germany and also in the Community Children's Hospital, St. Josef's Hospital, Freiburg. Infants and children were eligible when hospitalized due to RSV infection between September 1998 and March 2005 at an age of less than 2 years. RSV infection was detected by antigen test and/or RSV-specific PCR [16]. According to the case definition, children had symptoms of bronchiolitis, for example wheezing and tachypnoe and needed either supplementary oxygen and/or gavage feeding and/ or intravenous fluids. Children with congenital heart defects, immune deficiency or chromosomal aberrations were excluded. DNA samples were collected either by

Table I: Frequency and HWE of the polymorphisms within the three populations.

\begin{tabular}{|c|c|c|c|c|c|c|}
\hline Polymorphism & Asthma Frequency & HWE & RSV Frequency & HWE & Controls Frequency & HWE \\
\hline IL8 rs4073 (-25IA/T) & $0.44 I$ & 0.469 & 0.470 & 0.241 & 0.493 & 0.223 \\
\hline IL8 rs2227306 (-78IC/T) & 0.618 & 0.708 & 0.540 & 0.914 & 0.543 & 0.242 \\
\hline IL8RA rsI68588II (M3IR) & 0.969 & 1.000 & 0.974 & 1.000 & 0.954 & 1.000 \\
\hline IL8RA rsI 6858809 (S276T) & 0.933 & 1.000 & 0.948 & 1.000 & 0.944 & 1.000 \\
\hline IL8RA rsI6858808 (R335C) & 0.967 & 1.000 & 0.974 & 1.000 & 0.954 & $0.44 I$ \\
\hline
\end{tabular}

Results of genotyping of the IL8 and IL8RA variants on the three populations. The frequency is given for the wildtype allele. Also given is the p-value for the Hardy Weinberg Equilibrium (HWE) as calculated by Finetti. 
Table 2: Genotype distribution and p-values for association

\begin{tabular}{|c|c|c|c|c|c|c|}
\hline \multirow[t]{2}{*}{ Polymorphism } & \multicolumn{3}{|c|}{ Genotype distribution } & \multicolumn{3}{|c|}{ p-values for association } \\
\hline & Asthma & RSV & Controls & Asthma- Controls & RSV- Controls & Asthma- RSV \\
\hline IL8 rs4073 (-25IA/T) & $64 ; 148 ; 101$ & $26 ; 73 ; 34$ & $70 ; 124 ; 74$ & 0.087 & 0.550 & 0.425 \\
\hline IL8 rs2227306 (-78IC/T) & $123 ; 147 ; 48$ & $37 ; 62 ; 27$ & $84 ; 124 ; 61$ & 0.011 & 0.937 & 0.034 \\
\hline IL8RA rsI68588I I (M3IR) & $299 ; 20 ; 0$ & $128 ; 7 ; 0$ & $245 ; 25 ; 0$ & 0.174 & 0.152 & 0.655 \\
\hline IL8RA rs I 6858809 (S276T) & $239 ; 30 ; 0$ & $121 ; 14 ; 0$ & $121 ; 14 ; 0$ & 0.409 & 0.812 & 0.376 \\
\hline IL8RA rs I6858808 (R335C) & $298 ; 21 ; 0$ & 127; 7; 0 & $246 ; 23 ; 1$ & 0.239 & 0.171 & 0.584 \\
\hline
\end{tabular}

The genotype distribution within the three different populations is given in the following order: homozygous wildtype, heterozygous and homozygous mutation. Also listed are the $p$-values for association with the diseases as calculated by the Armitage's trend test.

blood taking or buccal smears with sterile cotton sticks. In total 131 children were included in this study.

\section{Control population}

270 randomly chosen probands, aged 19 to 40 years, served as controls. They originated from the same area in the South-Western part of Germany. No medical history was taken and no medical testing was performed on controls.

\section{Genotyping}

DNA was extracted from peripheral blood leucocytes or buccal smears following standard protocols and column purified (DNA midikit, Qiagen, Germany). The two IL8 polymorphisms $(-251 \mathrm{~A} / \mathrm{T}$ and $-781 \mathrm{C} / \mathrm{T})$ were typed as described previously [8].

The three IL8R polymorphisms were typed by means of restriction fragment length polymorphism (RFLP):

Met31Arg (rs16858811) was typed using the primer pair 5'-TGAAGATTACAGGCCCTGTA-3' and 5'-AAATCCAGCCATTCACCTTG-3'. Following PCR, the product was digested with two units of Bgll (Fermentas) at $37^{\circ}$ over night and the fragments were resolved on a $4 \%$ agarose gel.

Ser276Thr (rs16858809) was typed using the primer pair 5'-TCACCCTGCGTACACTGTTT-3' and 5'-GCCAAGAACTCCTTGCTGAC-3. Following PCR, the product was digested with one unit of Alw261 (Fermentas) at $37^{\circ} \mathrm{C}$ over night and the fragments were resolved on a $4 \%$ agarose gel.

Arg335Cys (rs16858808) was typed using the primer pair 5'-AGGAGTTCTTGGCACGTGAT -3' and 5'-AATGATGGTGCTTCGTTTCC-3'. Following PCR, the product was digested with one unit of DpnII (NEB) at $37^{\circ} \mathrm{C}$ over night and the fragments were resolved on $4 \%$ agarose gel.

\section{Sequencing}

For each polymorphism, three controls (homozygous wild type, heterozygous and homozygous mutation) were sequenced by the dideoxy chain termination method [17], using the Big Dye Terminator cycle sequencing kit on an ABI 310 sequencer (Applied Biosystems). All the following studies included these reference individuals.

\section{Statistical analysis}

Association analysis was performed for each polymorphism using Armitage's Trend Test. This test takes into account the individuals' genotypes rather than just the alleles, following the guidelines given by Sasieni [18], as implemented in the program Finetti (Thomas F. Wienker, unpublished data; http://ihg.gsf.de/cgi-bin/hw/hwa1.pl and http://ihg.gsf.de/linkage/download/finetti.zip). Hardy Weinberg equilibrium (HWE) was calculated for each polymorphism in all three populations using also the program Finetti. In addition to analyses based on single polymorphisms, we performed haplotype frequency estimations using the program FAMHAP [19]. The extent of linkage disequilibrium between polymorphisms has been calculated by Arlequin.

\section{Approval}

The collection of blood and the experimental procedures were approved by the Ethical Committee of the University of Freiburg. A statement of informed consent was signed by all participants; or in the case of children, signed by their parents.

\section{Results \\ Genotyping}

Five polymorphisms, two IL8 and three IL8RA polymorphisms, were typed on 131 children with severe RSV infection, 270 controls and 322 asthmatic children. The allelic frequencies of the polymorphisms in the three populations and the Hardy Weinberg equilibrium are given in table 1. All polymorphisms were in Hardy Weinberg equilibrium in all populations.

\section{Association studies}

The genotype distribution in the populations and the $\mathrm{p}$ values for association, obtained by Armitage's Trend Test, are listed in table 2. An association was observed between asthma and the promoter polymorphism -781C/T in IL8 
Table 3: Frequency of the haplotype within the three populations.

\begin{tabular}{|c|c|c|c|c|}
\hline & Haplotype & Asthma & RSV & Controls \\
\hline \multirow[t]{4}{*}{ IL8 } & I I & 0.061 & 0.029 & 0.038 \\
\hline & 12 & 0.380 & 0.443 & 0.455 \\
\hline & 21 & 0.558 & 0.503 & 0.504 \\
\hline & 22 & 0.002 & 0.024 & 0.004 \\
\hline \multirow[t]{3}{*}{ IL8RA } & I I I & 0.904 & 0.922 & 0.897 \\
\hline & 12 | & 0.065 & 0.052 & 0.055 \\
\hline & 212 & 0.031 & 0.026 & 0.044 \\
\hline
\end{tabular}

Number I refers to the wildtype allele, 2 to the variant allele.

$(\mathrm{p}=0.011)$. When comparing children with asthma to children with severe RSV infection, a significant different allelic distribution was observed for the same polymorphism ( $\mathrm{p}=0.0342)$. The other evaluated polymorphisms showed no association with bronchial asthma or severe RSV infection.

The two polymorphisms within IL8 were in very tight linkage disequilibrium in all populations $(p=0.00000$ for all possible pairs). Thus we did not perform Bonferroni correction for multiple testing as it would be far too conservative in this case. In IL8RA M31R and R35C were transmitted together ( $\mathrm{p}<0.0001$ for all populations).

\section{Haplotype analyses}

The haplotype pattern in all populations is given in table 3. IL8 haplotypes showed weak association with asthma ( $\mathrm{p}=0.036)$. Furthermore, haplotypes of IL8 were significantly differently distributed between asthmatics and children with severe RSV infection ( $p=0.005$; see table 4$)$. In contrast, no effect was seen with IL8RA haplotypes on either disease.

\section{Discussion}

So far, only few studies have investigated the impact of polymorphisms within the IL8 signaling pathway on the genetic background of severe RSV associated diseases or bronchial asthma. The IL8 pathway includes IL8 itself, its two receptor chains IL8RA and IL8RB and its degradative enzyme aminopeptidase $\mathrm{N}$ [20]. In a previous study, we have shown that IL8 polymorphisms are in association with bronchial asthma in the German population using 230 asthmatic children and 270 randomly chosen controls [8]. Furthermore, we hypothesized that polymorphisms within IL8 have opposite effects on the development of asthma and severe RSV infections. The hypothesis was based on the observation that the $-251 \mathrm{~T}$ allele was more common in patients with asthma than in controls. In contrast, two studies from Hull and colleagues have demonstrated that the opposite allele, that is
Table 4: Results of the haplotype analyses using FAMHAP.

\begin{tabular}{lccc}
\hline & Asthma-Controls & RSV-Controls & RSV-Asthma \\
\hline IL8 & 0.036 & 0.180 & 0.005 \\
IL8RA & 0.448 & 0.729 & 0.724 \\
\hline
\end{tabular}

$-251 \mathrm{~A}$, is associated with severe RSV infection in the English population $[9,10]$.

Thus the first aim of the current study was to test whether our initial hypothesis of an opposite role of IL8 polymorphisms on asthma and RSV infections holds in a population of German children with severe RSV associated diseases. Second, we wanted to verify the association between bronchial asthma and IL8 polymorphisms in an extended asthmatic population (increased by 90 asthmatic children to 320 probands). Thirdly, we extended our investigation to include IL8RA as recently association of asthma and chronic obstructive pulmonary disease with this gene has been reported in another German samples [13].

In the here presented study, the polymorphisms $-251 \mathrm{~A} / \mathrm{T}$ and $-781 \mathrm{C} / \mathrm{T}$ within IL8 showed no association with severe RSV associated diseases - neither in analyses of single polymorphisms nor in haplotype analyses. This might suggest that IL8 does not play a major role in the development of severe RSV infections in the German population. These findings are in contrast to the above mentioned studies of Hull et al. $[9,10]$. The discrepancy could be due to several reasons: The infants included in the study of Hull et al. were younger than in our study. Furthermore, the inclusion criteria differed slightly between both studies, for example, Hull and colleagues included children with pre-existing heart diseases, whereas we excluded those children. Finally, though the English and German population represent both Caucasians it is well known that the genetic predisposition to allergic diseases are at least partially different between Germans and English people [21].

The association between bronchial asthma and -781C/T within IL8 could be confirmed in an extended asthmatic population $(\mathrm{p}=0.011)$, whereas the association with the second IL8 polymorphism $-251 \mathrm{~A} / \mathrm{T}$ and asthma became weaker and was no longer statistically significant $(\mathrm{p}=$ 0.087 ). This might be in accordance to one study, showing that $-251 \mathrm{~A} / \mathrm{T}$ has no functional impact, whereas the base pair substitution $\mathrm{C}$ to $\mathrm{T}$ at position -781 within the IL8 promotor enhances the binding of transcription factors and thus is probably more important in the genetic regulation of IL8 expression [22]. 
Furthermore, a direct comparison of the asthmatic population with the RSV population revealed significant differences, both for $-781 \mathrm{C} / \mathrm{T}$ alone $(\mathrm{p}=0.034)$ as well as in the haplotype analyses $(p=0.005)$. These results may support our initial hypothesis, that polymorphisms within IL8 have opposite effects in the pathophysiology of asthma and RSV associated diseases. However, one should notice, that the allelic frequencies of the polymorphisms did not markedly differ between controls and children with severe RSV infections. Thus the positive association might merely reflect the fact that the genotype frequencies in asthmatics differ from controls.

In contrast to Stemmler et al, who found that the IL8RA polymorphisms M13R and R335C were significantly associated with bronchial asthma [13], we found no association of these polymorphisms neither with asthma nor severe RSV associated diseases. Again the conflicting results might be due to different inclusion criteria. The study by Stemmler $e$ t al. used 68 adult patients and 130 children with asthma whereas we used exclusively children with asthma. The "adult phenotype" of asthma is quite different from the asthmatic phenotype in children. For example pediatric asthma is much more often allergic than asthma in adults. Thus it might not be surprising that the genetic background of asthma differs between adults and children [23]. Furthermore, the size of our asthmatic study population was larger than the population of Stemmler et al. (198 asthmatic patients versus 320 patients). Thus the significant result in their study might just reflect a type 1 error. However, as the risk factor conferred by a single gene is quite small in complex genetic diseases like asthma, it is also possible that we missed true association in our population due to a type 2 error.

\section{Conclusion}

We conclude from our data, that IL8 might play a role in the genetic predisposition to bronchial asthma and that these effects are different, or maybe even opposite to the effects of the same polymorphisms on severe RSV associated diseases. In contrast IL8RA polymorphisms do not play a major role, neither in the development of severe RSV infections nor in asthma.

\section{Competing interests}

The author(s) declare that they have no competing interests.

\section{Authors' contributions}

BP performed genotyping and sequencing of IL8 polymorphisms as well as the statistical analyses and drafted the manuscript.

MK participated in the clinical design of the study and the recruitment of the RSV population.
JH performed genotyping and sequencing of IL8RA polymorphisms

JF participated in the clinical design of the study.

AH conceived and coordinated the study and helped to draft the manuscript.

All authors have read and approved the final manuscript.

\section{Acknowledgements}

This project was supported by grants from the Deutsche Forschungsgemeinschaft (DFG HE 3|23/3-I and DFG HE 3|23/4-2). The recruitment of asthmatic children was partially supported by a grant from the $\mathrm{NIH}(\mathrm{NIH}$ ROI HL66533-0I).

\section{References}

I. Harada A, Sekido N, Akahoshi T, Wada T, Mukaida N, Matsushima K Essential involvement of interleukin-8 (IL8) in acute inflammation. J Leukoc Biol 1994, 56:559-564.

2. Sigurs N, Gustafsson PM, Bjarnason R, Lundberg F, Schmidt S, Sigurbergsson $F$, Kjellman B: Severe respiratory syncytial virus bronchiolitis in infancy and asthma and allergy at age $13 . \mathrm{Am} J$ Respir Crit Care Med 2005, I 7 I: I37-4I.

3. Sigurs N, Bjarnason R, Sigurbergsson F, Kjellman B: Respiratory syncytial virus bronchiolitis in infancy is an important risk factor for asthma and allergy at age 7. Am J Respir Crit Care Med 2000, 161:1501-7.

4. Stein RT, Sherrill D, Morgan W, Holberg C], Halonen M, Taussig LM, Wright AL, Martinez FD: Respiratory syncytial virus in early life and risk of wheeze and allergy by age 13 years. Lancet 1999 , 354:54I-5.

5. Norzila MZ, Fakes K, Henry RL, Simpson J, Gibson PG: Interleukin8 secretion and neutrophil recruitment accompanies induced sputum eosinophil activation in children with acute asthma. Am J Respir Crit Care Med 2000, 161:769-74.

6. Fujimura M, Xiu Q, Tsujiura M, Tachibana H, Myou S, Matsuda T, Matsushima K: Role of leukotriene B4 in bronchial hyperresponsiveness induced by interleukin-8. Eur Respir J 1998, II I:306-II.

7. Xiu Q, Fujimura M, Nomura M, Saito M, Matsuda T, Akao N, Kondo $\mathrm{K}$, Matsushima $\mathrm{K}$ : Bronchial hyperresponsiveness and airway neutrophil accumulation induced by interleukin-8 and the effect of the thromboxane A2 antagonist S-1452 in guineapigs. Clin Exp Allergy 1995, 25:5I-9.

8. Heinzmann A, Ahlert I, Kurz T, Berner R, Deichmann KA: Association study suggests opposite effects of polymorphisms within IL8 on bronchial asthma and respiratory syncytial virus bronchiolitis. J Allergy Clin Immunol 2004, I | 4:67I-6.

9. Hull J, Ackerman $H$, Isles $K$, Usen S, Pinder M, Thomson A, Kwiatkowski D: Unusual haplotypic structure of IL8, a susceptibility locus for a common respiratory virus. Am J Hum Genet 200I, 69:413-9.

10. Hull J, Thomson A, Kwiatkowski D: Association of respiratory syncytial virus bronchiolitis with the interleukin 8 gene region in UK families. Thorax 2000, 55:1023-7.

II. Holmes WE, Lee J, Kuang WJ, Rice GC, Wood WI: Structure and functional expression of a human interleukin-8 receptor. Science 1991, 253: I 278-80.

12. Xu J, Postma DS, Howard TD, Koppelman GH, Zheng SL, Stine OC, Bleecker ER, Meyers DA: Major genes regulating total serum immunoglobulin E levels in families with asthma. Am J Hum Genet 2000, 67:1163-73.

13. Stemmler S, Arinir U, Klein W, Rohde G, Hoffjan S, Wirkus N, Reinitz-Rademacher K, Bufe A, Schultze-Werninghaus G, Epplen JT: Association of interleukin-8 receptor alpha polymorphisms with chronic obstructive pulmonary disease and asthma. Genes Immun 2005, 6:225-30.

14. The International Study of Asthma and Allergies in Childhood (ISAAC) Steering Committee: Worldwide variation in prevalence of symptoms of asthma, allergic rhinoconjunctivitis, and atopic eczema: ISAAC. Lancet 1998, 35 I:|225-32. 
15. Heinzmann A, Jerkic SP, Ganter K, Kurz T, Blattmann S, Schuchmann L, Gerhold K, Berner R, Deichmann KA: Association study of the variant Arg I I OGIn in Interleukin- 13 with atopic diseases and juvenile idiopathic arthritis. J Allergy Clin Immunol 2003, I 1 2:735-39.

16. Forster J, Ihorst $G$, Rieger $\mathrm{CH}$, Stephan V, Frank HD, Gurth H, Berner R, Rohwedder A, Werchau H, Schumacher M, Tsai T, Petersen G: Prospective population-based study of viral lower respiratory tract infections in children under 3 years of age (the PRI.DE study). Eur J Pediatr 2004, 163:709-16.

17. Sanger $F$, Nicklen S, Coulson AR: DNA sequencing with chainterminating inhibitors. Biotechnology 1992, 24:104-8.

18. Sasieni PD: From genotypes to genes: doubling the sample size. Biometrics 1997, 53:1253-61.

19. Becker T, Knapp M: Maximum-likelihood estimation of haplotype frequencies in nuclear families. Genet Epidemiol 2004, 27:21-32.

20. Palter SF, Mulayim N, Senturk L, Arici A: Interleukin-8 in the human. J Clin Endocrinol Metab 200I, 86:2660-7.

21. Kurz T, Strauch K, Heinzmann A, Braun S, Jung M, Ruschendorf $F$, Moffatt MF, Cookson WO, Inacio F, Ruffilli A, Nordskov-Hansen G, Peltre G, Forster J, Kuehr J, Reis A, Wienker TF, Deichmann KA: A European study on the genetics of mite sensitization. J Allergy Clin Immunol 2000, 106:925-32.

22. Hacking D, Knight JC, Rockett K, Brown H, Frampton J, Kwiatkowski DP, Hull J, Udalova IA: Increased in vivo transcription of an IL8 haplotype associated with respiratory syncytial virus diseasesusceptibility. Genes Immun 2004, 5:274-82.

23. Bottema RW, Reijmerink NE, Koppelman GH, Kerkhof M, Postma DS: Phenotype definition, age, and gender in the genetics of asthma and atopy. Immunol Allergy Clin North Am 2005, 25:62I-39.

\section{Publish with Bio Med Central and every scientist can read your work free of charge}

"BioMed Central will be the most significant development for disseminating the results of biomedical research in our lifetime. "

Sir Paul Nurse, Cancer Research UK

Your research papers will be:

- available free of charge to the entire biomedical community

- peer reviewed and published immediately upon acceptance

- cited in PubMed and archived on PubMed Central

- yours - you keep the copyright

Submit your manuscript here:

http://www.biomedcentral.com/info/publishing_adv.asp 